\title{
Scientific Basis and Practical Application of Nutritional Care for Preterm Infants
}

Improvements in perinatal and neonatal care have markedly increased the survival of premature infants during the last two decades, in particular of infants born very preterm or extremely preterm. Accordingly, the attention of both families and medical caregivers has increasingly shifted from a focus on survival and avoidance of severe complications, to a focus on quality of survival and later outcome. This led to an increased attention to nutritional care of preterm infants, since considerable evidence has shown that the quality of nutrition of preterm infants is not only related to infant growth, immediate functions, and length of hospital stay, but also to long-term health and quality of life.

In this book, we present guidance for the practical application of nutritional care of preterm infants, based on a critical evaluation of current clinical and scientific evidence. Leading experts from around the globe summarized the current knowledge in their area of expertise in their book chapters, with an emphasis on deriving key messages for clinical application. The manuscripts were critically peer reviewed each by at least two external experts and two editors, and authors revised and improved the manuscripts accordingly. In addition, all editors and authors extensively discussed the recommendations and provided advice for further improvements, and they also held a formal consensus process on the quantitative recommendations during three meetings of all authors held in October and November 2020. We were most impressed by the dedication of our participating colleagues and the high quality of the discussions. In addition, we very much enjoyed the process and the spirit of collaboration and friendship that we experienced during the production of this book. 
We gratefully acknowledge the solid basis on which we build, created by the preceding books conceived and edited by Prof. Reginald Tsang who worked at the Cincinnati Children's Hospital Medical Center. He aimed to address the "need to give tentative answers to 'real-life situations' of the preterm infant in the nursery" in the books Vitamin and Mineral Requirements in Preterm Infants published in 1985 [1], Nutritional Needs of the Preterm Infant: Scientific Basis and Practical Guidelines published in 1993 [2], and Nutrition of the Preterm Infant: Scientific Basis and Practical Application published in 2005 [3]. We tried to follow this tradition in the previous edition of this book [4] and in the current edition. It is our hope that the current book will facilitate the daily practice of busy clinicians and will contribute to raising the standards of nutritional care for preterm infants around the world.

\section{Acknowledgment}

The editors thank Karger Publishers, Basel, Switzerland, and particularly Yvonne Rebmann for the dedicated help in developing this book project, and Mead Johnson Nutrition Institute for providing a grant to Karger Publisher to support dissemination of this book, which did not in any way influence the content.

Berthold Koletzko, Munich

Fook-Choe Cheah, Kuala Lumpur

Magnus Domellöf, Umeå

Johannes B. van Goudoever, Amsterdam

Brenda B. Poindexter, Atlanta, GA

Nestor Vain, Buenos Aires

\section{References}

1 Tsang RC, editor. Vitamin and mineral requirements in preterm infants. New York: Dekker; 1985.

2 Tsang RC, Lucas A, Uauy R, Zlotkin S, editors. Nutritional needs of the preterm infant: scientific basis and practical guidelines. Baltimore: Williams \& Wilkins; 1993.
3 Tsang RC, Uauy R, Koletzko B, Zlotkin S, editors. Nutrition of the preterm infant. Scientific basis and practical application. Cincinnati: Digital Educational Publishing; 2005.

4 Koletzko B, Poindexter B, Uauy R, editors. Nutritional care of preterm infants. Basel: Karger; 2014. 